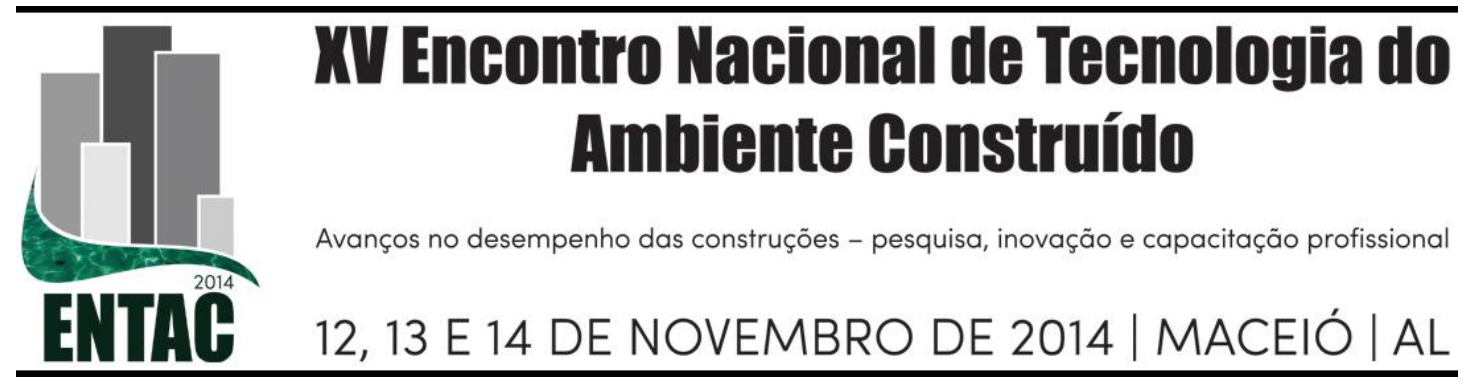

\title{
SERVIÇOS DE MANUTENÇÃO EM HABITAÇÃO DE INTERESSE SOCIAL COM SISTEMA CONSTRUTIVO NÃO CONVENCIONAL: UMA ANÁLISE DOS CUSTOS A PARTIR DA SITUAÇÃO SOCIOECONÔMICA DOS MORADORES
}

\author{
SILVA, Maisa Beatriz M. Fausto da (1); TEIXEIRA, Dimas de Assis Albuquerque \\ (2); MEIRA, Alexsandra Rocha (3); ARAÚJO, Nelma Mirian Chagas de (4) \\ (1) UFPB, biafausto@hotmail.com; (2) IFPB, dimasteixeira@yahoo.com.br; (3) IFPB, \\ alexmeira@uol.com.br; (4) IFPB,nelmamca@gmail.com
}

\begin{abstract}
RESUMO
O artigo em foco é resultado de uma pesquisa exploratória descritiva que expõe as fragilidades das construções advindas, principalmente, da falta de manutenção adequada e frequente. Foram estudadas dez habitações de interesse social do Conjunto Habitacional Mariz I, localizado na cidade de João Pessoa-PB, datadas do final da década de 90 e construídas com paredes em placas de concreto moldadas in loco. Esse trabalho visa analisar as moradias, no que diz respeito aos custos de manutenção, e investigar a influência da situação socioeconômica dos moradores nesses custos. Para a realização da pesquisa procedeu-se inicialmente com o estudo da manutenção, detalhando, entre outros, todos os serviços realizados e seus respectivos custos. Os moradores foram entrevistados, visando traçar o perfil socioeconômico da população envolvida. As análises foram conduzidas, revelando, assim, o predomínio de manutenção corretiva, além de indícios da relação entre o poder aquisitivo dos moradores e o tipo de manutenção adotada. Os resultados mostraram que os valores dos custos de manutenção das residências foram diretamente proporcionais ao poder aquisitivo dos respectivos moradores, correspondendo, em média, a $4 \%$ de suas rendas. Por fim, o estudo pretende mostrar que, para os programas de habitação de interesse social oferecerem edificações compatíveis com os rendimentos dos futuros residentes, é fundamental que, além do rigor técnico, essencial em qualquer empreendimento, efetue-se uma melhor investigação das condições socioeconômicas dos usuários, bem como da sua interferência na manutenção das construções.
\end{abstract}

Palavras-chave: Manutenção, Habitação de interesse social, Sistema construtivo não convencional, situação socioeconômica

\begin{abstract}
This article aims at to present the results of an exploratory descriptive research about construction maintenance. Ten houses were selected from the social housing Mariz I, located in João Pessoa city. The houses, dated from the late 90's, were built with walls of concrete slabs made on site. This work analyzes the houses in relation to maintenance costs and investigates the influence of socioeconomic status of residents in these costs. Initially the socioeconomic characteristics of the residents, all maintenance services and their costs were studied. Thereafter the results were analyzed. They show the prevalence of corrective maintenance as well as evidence of the relationship between the purchasing power of residents and type of maintenance adopted. The results showed that the values of the maintenance costs of the residences were directly proportional to the purchasing power of its inhabitants, corresponding on average to $4 \%$ of their income. Finally, this study shows that for programs to provide social housing compatibles with the users it is essential that, in addition to technical rigor, make a better investigation of the socioeconomic conditions of the users, as well as their interference in the maintenance buildings.
\end{abstract}

Keywords: Maintenance, social housing, unconventional building system, socioeconomic status 


\section{INTRODUÇÃO}

A questão habitacional teve sua origem nas transformações sociais, políticas, econômicas e culturais ocorridas no século XVIII, em decorrência da Revolução Industrial (NUNES 2008). Na segunda metade do século XIX, com o capitalismo, começou a se constituir no Brasil, a problemática da habitação popular urbana.

Em João Pessoa, na segunda metade do século $\mathrm{XX}$, a criação do novo 'Distrito Industrial' traz para o meio urbano os trabalhadores rurais, cujos baixos salários, desemprego ou subemprego, proporcionou o surgimento, de novos conjuntos habitacionais de baixa renda e sub-moradias (TINEM, CARVALHO, 2005).

Nesse contexto foi inserido o termo Habitação de Interesse Social (HIS), que define uma série de soluções de moradia voltadas à população de baixa renda (ABIKO, 1995).

Assim como o problema da habitação popular urbana, a falta de preservação das habitações é algo que persiste desde muito tempo. Tendo em vista isto Freitas (2009) afirma que as edificações são construídas para durarem muitos anos, porém, no momento em que são entregues aos usuários, elas começam a sofrer vários tipos de degradação, tornando a manutenção necessária.

No âmbito das habitações de interesse social (HIS), a realização de manutenção é ainda mais difícil, uma vez que o poder aquisitivo dos moradores é limitado. Como consequência, quando se recorre à manutenção, essencialmente associa-se à informalidade. Logo, quando as HIS são construídas com algum sistema construtivo não convencional, a manutenção requer ainda mais cautela, uma vez que demanda conhecimento técnico mais aprofundado, ferramentas e mão de obra específica, e esse conhecimento prévio nem sempre é acessível aos usuários desse tipo de edificação.

Diante dessa problemática, buscou-se, na presente pesquisa, compreender as implicações da realidade socioeconômica das famílias sobre as manutenções realizadas nas HIS em estudo.

Voltando-se um pouco para os aspectos conceituais, o termo manutenção teve sua origem junto aos militares, com o significado de manter, o efetivo e os equipamentos bélicos em condições de combate. Já na década de 50, tanto nos Estados Unidos como na França, manutenção passou a ser um termo utilizado na indústria, no sentido de conservação (MONCHY, 1989 apud ANTUNES, 2004). No âmbito da construção civil, Gomide (2006) definiu manutenção como o conjunto de atividades que garantem o melhor desempenho da edificação, para atender às necessidades dos usuários. De forma complementar, a NBR 15575 (ABNT, 2013) relaciona manutenção a um conjunto de atividades a serem realizadas ao longo da vida total da edificação, para conservar ou recuperar a sua capacidade funcional e de seus sistemas constituintes de atender às necessidades e segurança dos seus usuários. Tanto a literatura quanto a prática demonstram que todas as intervenções necessárias, em termos de manutenção, implicam em despesas, ou seja, os conhecidos custos de manutenção.

Segundo El-Haram e Horner (2002), os custos de manutenção incluem todas as despesas necessárias para se manter a edificação em níveis aceitáveis; sendo os mesmos bastante variados. De acordo com o mesmo autor esses custos dependem dos seguintes fatores: [i] características das construções; [ii] fatores relacionados aos próprios moradores; [iii] características da manutenção; [iv] aspectos relacionados à política pública; [v] outros. Embora os custos de manutenção sofram várias influências, em geral, Booty (2006, apud OLANREWAJU et al., 2011) afirma que 75\% das despesas totais de uma edificação ao longo da vida útil são atribuídas à manutenção. 
Diante da importância da manutenção, a mesma deve ser feita de forma estruturada (WAEYENBERGH e PINTELON, 2002). A NBR 5674 (ABNT, 2012) adverte que a manutenção não deve ser realizada improvisadamente e casualmente, mas fundamentada em procedimentos organizados e, com o controle de custos.

Com base nessas considerações, este artigo foi desenvolvido, buscando contextualizar os custos de manutenção de um conjunto de dez habitações de interesse social que utilizam sistema construtivo inovador com os perfis socioeconômicos dos moradores.

\section{OBJETIVO GERAL}

O presente trabalho tem como objetivo verificar a influência da situação socioeconômica dos moradores de habitações de interesse social (HIS), construídas com sistema construtivo inovador, nos custos de manutenção das respectivas edificações.

\section{MATERIAIS E MÉTODOS}

Este artigo é resultado de uma pesquisa mais abrangente, desenvolvida a partir das etapas descritas a seguir.

Pesquisa bibliográfica - fundamentada em bibliografia nacional e internacional relacionada à temática de manutenção e aos custos resultantes dessa atividade.

Seleção das construções - em contato com a Companhia de Habitação do Estado da Paraíba (CEHAP), foram investigadas habitações de interesse social (HIS) construídas com algum sistema inovador. Com esse perfil, identificou-se o Conjunto Habitacional Mariz I, localizado na cidade de João Pessoa, cujas unidades habitacionais foram entregues aos moradores no ano de 1998. Em função disso, todas as análises realizadas no artigo se referem ao período compreendido entre o início do uso e o ano de 2013.

Visita preliminar - com o objetivo de conhecer a realidade das habitações, em termos de estrutura física, e ter uma visão geral da dinâmica de alterações construtivas realizadas ao longo dos anos, procedeu-se com uma visita inicial no local de estudo.

Elaboração de questionário socioeconômico - com o objetivo de traçar o perfil socioeconômico dos moradores, e suas influências nos custos de manutenção, foi elaborado um questionário padrão com perguntas concernentes a essa temática.

Elaboração de formulário de entrevista - com o objetivo de ajudar na pesquisa de campo, no tocante aos aspectos técnicos, elaborou-se um formulário de entrevista, onde foram contemplados os elementos construtivos passíveis de manutenção.

Pesquisa de campo - foram selecionadas, de forma aleatória, 10 (dez) unidades para a realização da pesquisa (aplicação do questionário, bem como do formulário de entrevista). Além disso, uma vez que nem todos os custos foram obtidos diretamente através das entrevistas com os moradores, foram realizadas in loco medições dos serviços executados ao longo dos anos.

Montagem de planilhas orçamentárias - a partir dos dados obtidos em campo, foram elaboradas as planilhas, usando-se como referência os valores dos insumos atualizados e dos coeficientes de consumo de mão de obra e de materiais que compõem a base do SINAPI (Sistema Nacional de Pesquisa de Custos e Índices da Construção Civil). O 
valor da mão de obra foi baseado no SINTRICOM-JP (Sindicato Intermunicipal dos Trabalhadores nas Indústrias da Construção Civil, da Construção Pesada e do Mobiliário, de João Pessoa) e foram excluídos das composições os encargos sociais, visando uma aproximação da realidade dos moradores. Os custos de insumos e mão de obra foram retroagidos, aplicando-se o INCC (Índice Nacional de Custo da Construção), para então se poder traçar a evolução dos custos ao longo dos anos.

Análise dos dados - Os dados obtidos foram analisados, no software Excel e para se proceder com a uniformização, os mesmos estão expressos em $\mathrm{R} \$ / \mathrm{m}^{2}$.

\section{CARACTERIZAÇÃO DO OBJETO DE ESTUDO}

Entre os anos de 1998 e 2002, o órgão paraibano responsável pela construção de HIS, a CEHAP, construiu mais de 7.000 (sete mil) moradias com sistema construtivo inovador e, dessas, 480 (quatrocentos e oitenta) estão em João Pessoa; as mesmas possuem em torno de $33,50 \mathrm{~m}^{2}$ de área, contendo 27 (vinte e sete) pilares em concreto armado, 127 (cento e vinte e sete) placas de vedação, em concreto pré-moldado, cujas paredes formadas receberam pintura a cal, as telhas são do tipo canal, as instalações hidrossanitárias e elétricas são aparentes e as esquadrias são de madeira, pintadas com esmalte sintético.

Figura 1- planta baixa do Conjunto Mariz I

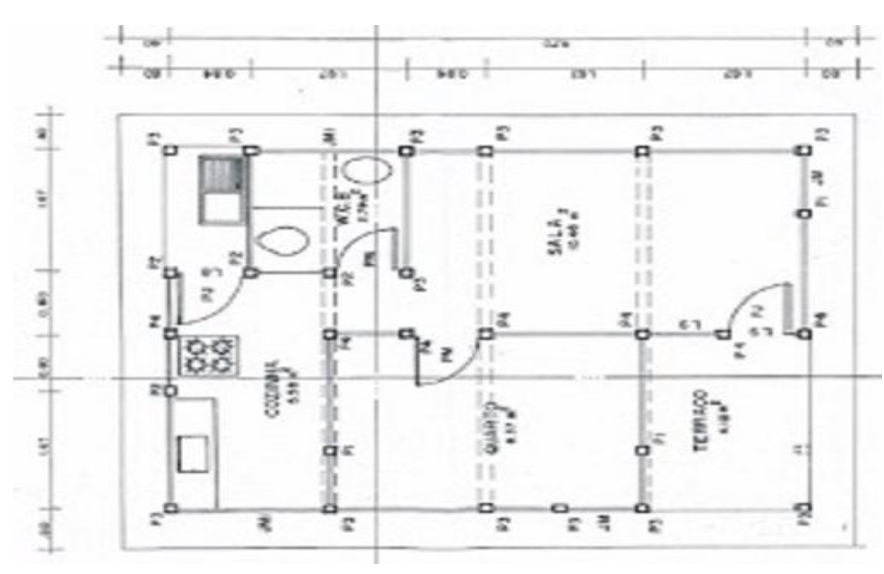

Fonte: Projeto da CEHAP - 1995

\section{Figura 2- Fachada frontal das casas 4 e 5 do Conjunto Mariz I}

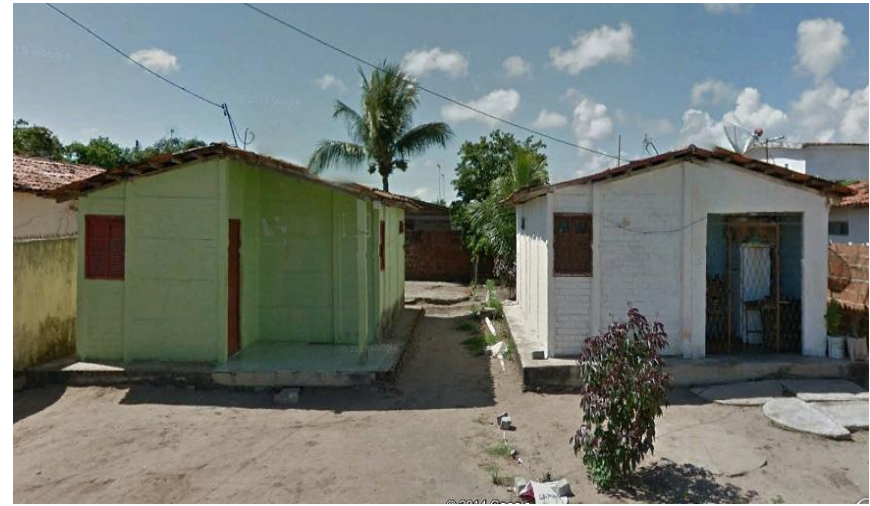

Fonte: acervo dos autores - 2013 


\section{RESULTADOS E DISCUSSÕES}

Os resultados e as análises estão fundamentados no traçado socioeconômico dos usuários das edificações, na análise quantitativa dos custos de manutenção e, por fim, análise da relação entre a situação socioeconômica dos usuários e as suas despesas com manutenção.

\subsection{Perfil socioeconômico dos moradores}

A estrutura familiar encontrada na maioria dos casos é formada por um núcleo composto por um casal e uma quantidade variada de filhos. O número médio de pessoas na moradia é de 3,5 indivíduos (no mínimo 3 e no máximo 5 pessoas). Quanto ao tempo de moradia, todos os 10 entrevistados, proprietários das unidades, lá residem desde a entrega do conjunto, há 16 anos.

No tocante à renda mensal familiar, através dos dados constantes na Figura 3, percebese que as casas com as maiores rendas mensais são: casa 1, casa 2, casa 7 e a casa 8; em contrapartida as casas com as menores rendas são: casa 3 e casa 4 .

\section{Figura 3- Renda mensal familiar dos moradores das habitações}

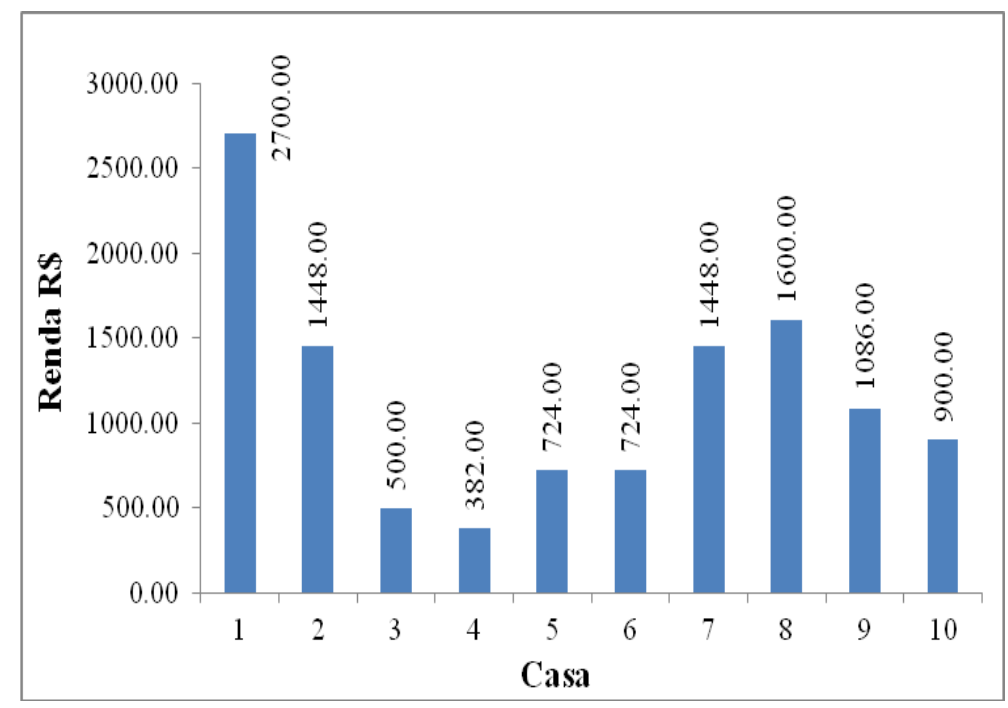

Fonte: acervo dos autores - 2013

\subsection{Análise quantitativa dos custos de manutenção}

Edificações novas, geralmente, demandam pouca manutenção. Entretanto, com o tempo, conforme Freitas (2009), a manutenção se faz necessária. Nas moradias analisadas, isso é ratificado (Figura 4). Além disso, convém destacar que o crescimento das despesas com manutenção nas HIS estudadas, conforme exposto na Figura 4, é resultante, entre outros, de dois fatos consideráveis: o natural incremento dos preços e o avanço da degradação dos componentes da construção.

Conforme citado anteriormente, o estudo de El-Haram e Horner (2002) afirma que vários fatores podem influenciar nos custos de manutenção de edificações. Tais fatores concorreram para esta postura atípica dos moradores, que, por motivos alheios à pesquisa, não priorizaram a manutenção da sua habitação. Portanto, para se chegar às causas do comportamento dos custos no ano de 2013, faz-se necessário uma pesquisa mais específica, que busque essas respostas. 
Figura 4- Evolução dos custos de manutenção (em anos) - 10 casas

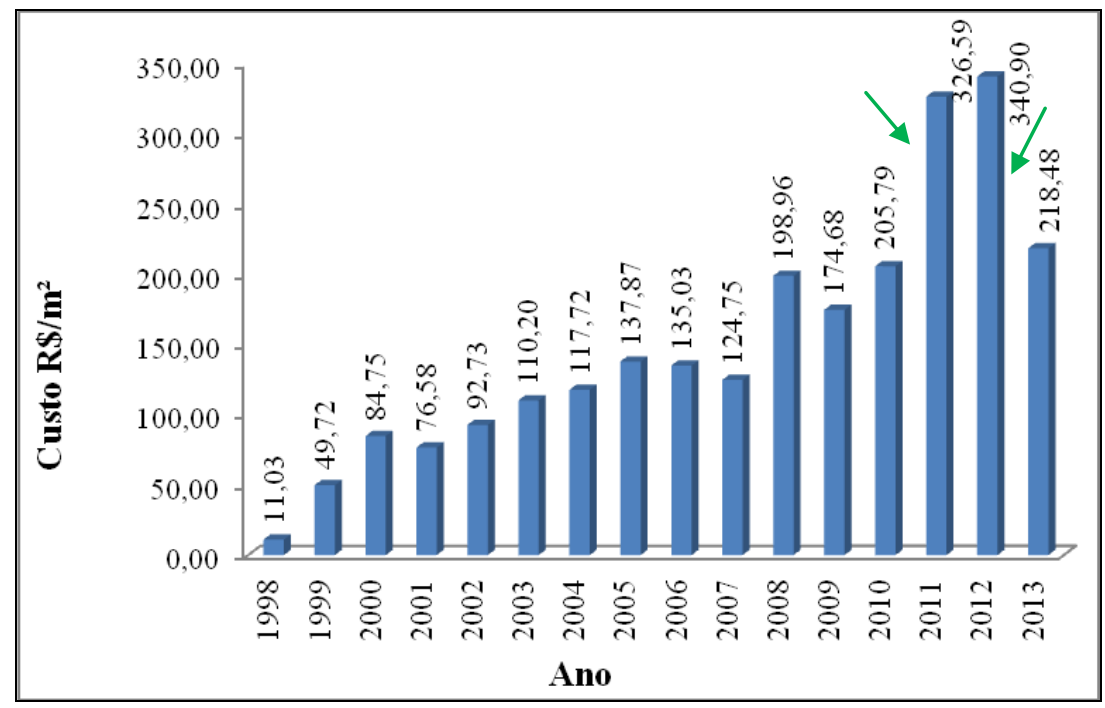

Fonte: acervo dos autores - 2013

A Figura 5 traz os custos de manutenção por item de serviço. O gráfico evidencia que mais de $90 \%$ dos recursos foram destinados para a pintura. Segundo os entrevistados, boa parte dos serviços expostos no gráfico da Figura 4, só são efetuados quando a situação se torna crítica.

Figura 5- Custo médio por itens de manutenção e percentual acumulado (Gráfico de Pareto)

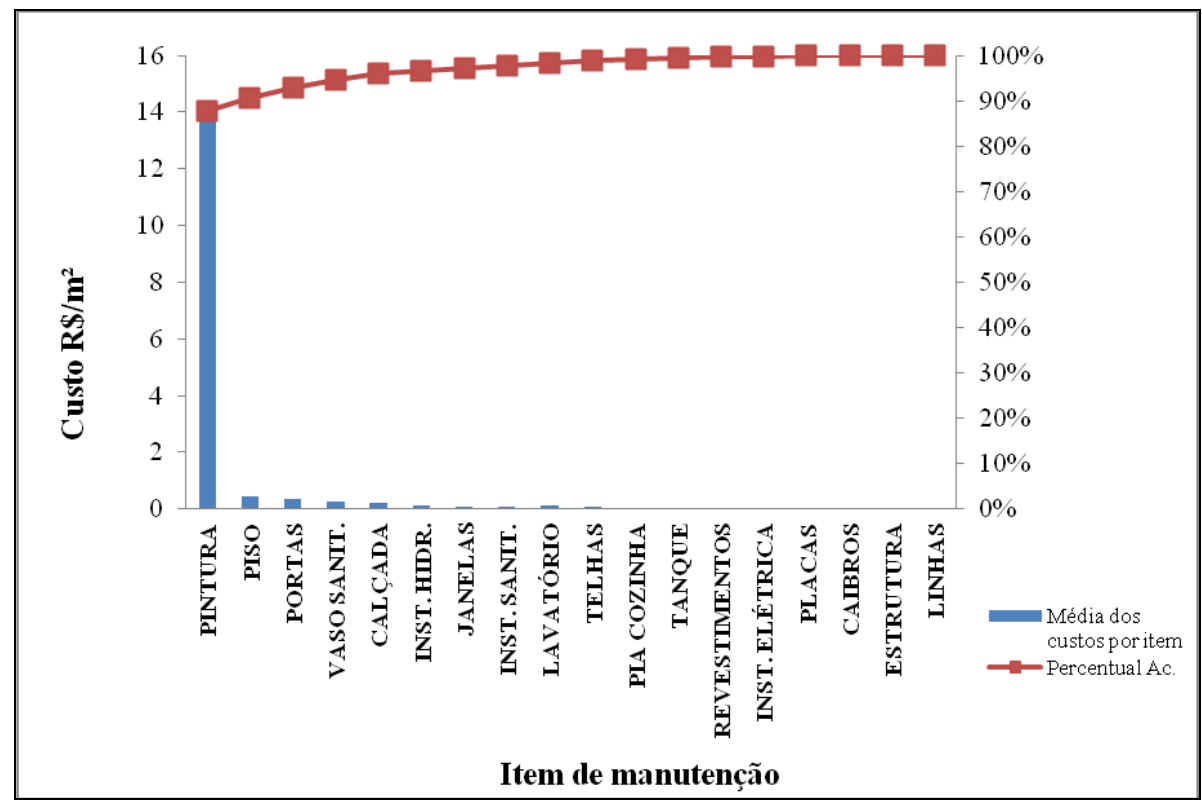

Fonte: acervo dos autores - 2013

A Figura 6 retrata os custos totais com manutenção de cada casa ao longo do período estudado. Pode-se observar que as casas 1, 2, 7 e 8 destinaram maiores recursos financeiros aos serviços de manutenção ao longo do período estudado. 
Figura 6- Custos totais por $\mathbf{m}^{2}$ das habitações em estudo

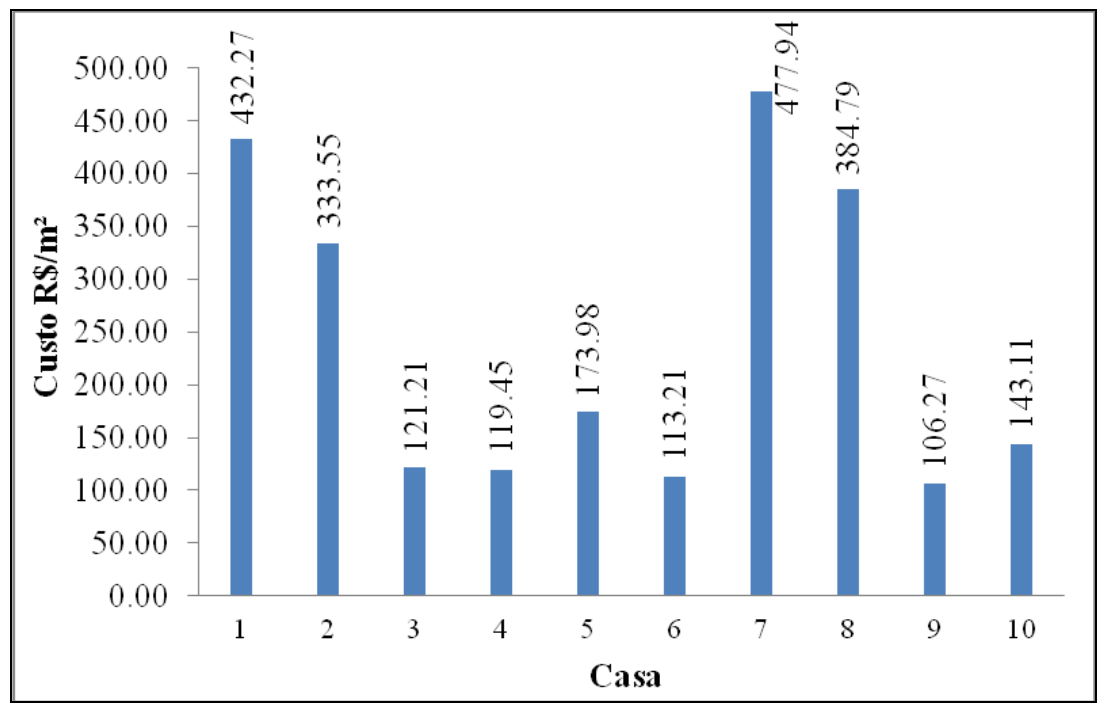

Fonte: acervo dos autores - 2013

\subsection{Perfil socioeconômico dos moradores e custos de manutenção}

Confrontando os dados referentes à renda e aos custos de cada casa, conforme consta na Figura 7, constata-se que os valores dos custos de manutenção foram mais expressivos justamente onde há um maior poder aquisitivo, e menores onde os moradores possuem menor renda. Embora as diferenças, em termos de renda, não sejam significativas, e os moradores estejam enquadrados em classes sociais semelhantes, conforme classificação da Secretaria de Assuntos Estratégicos do Governo Federal (SAE, 2014 a; 2014 b), ainda assim foram observadas diferenças nos gastos com manutenção. A média de renda entre eles foi de aproximadamente 1,6 salários, tendo um desvio padrão em torno de 0,9 salários.

Figura 7- Análise comparativa entre a renda mensal familiar e os custos com manutenção de cada casa

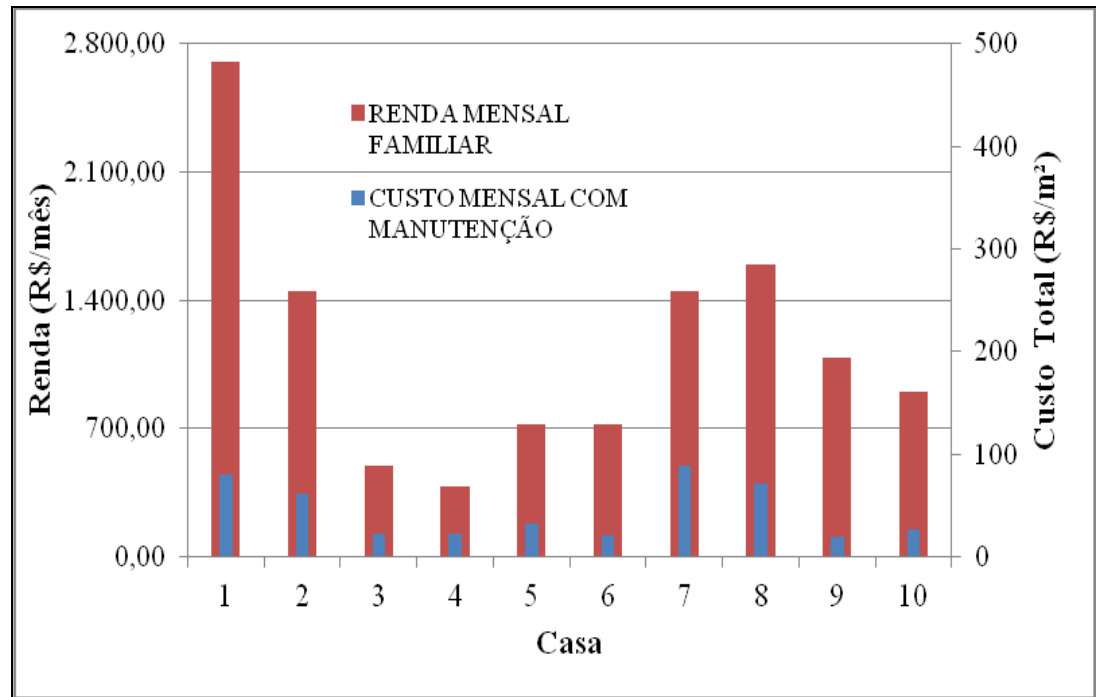

Fonte: acervo dos autores - 2014 
A seguir, apresentam-se resultados relativos à relação entre a renda dos moradores das HIS e os seus respectivos custos com manutenção. Para isso, expõe-se o percentual mensal da renda de cada família destinado aos custos com a manutenção de cada casa ao longo dos anos. Visando facilitar o entendimento da questão, excepcionalmente na análise exibida na Figura 8, se fez uso do valor absoluto mensal dos custos, diferentemente do procedimento até aqui empregado, no qual estão padronizadas as referidas despesas, em Real $(\mathrm{R} \$)$ por metro quadrado $\left(\mathrm{m}^{2}\right)$.

\section{Figura 8 - Percentual do custo total de manutenção em relação à renda mensal familiar}

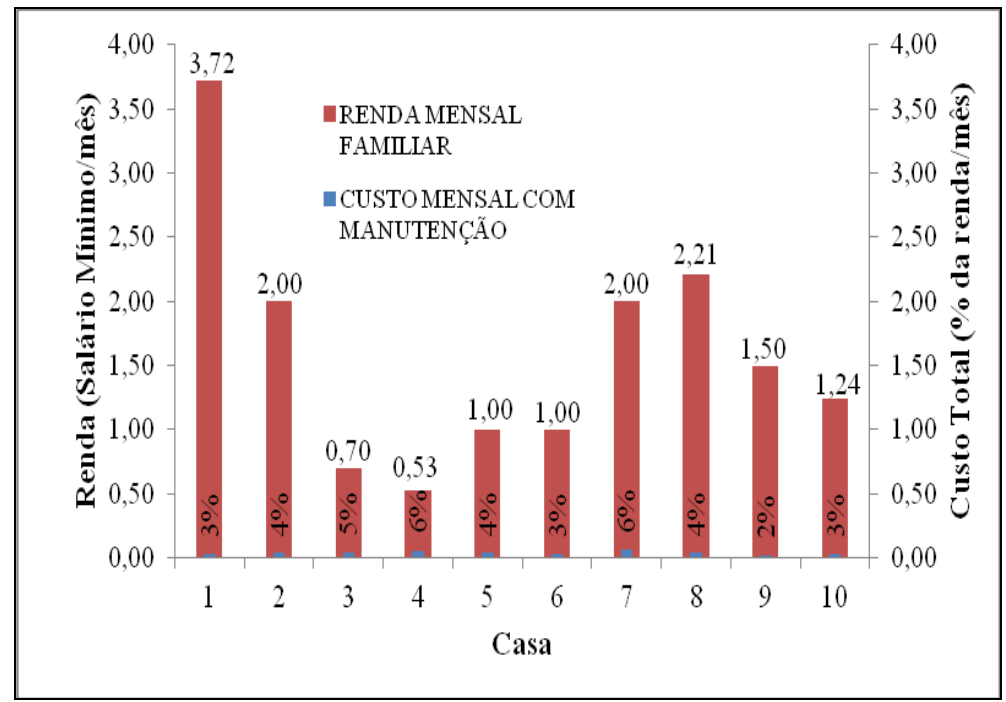

Fonte: acervo dos autores - 2014

As famílias dessas habitações, em geral, empregam suas rendas nas despesas de água, luz, transporte, alimentação, entre outras prioridades. Frente a essa realidade, pouco ou nada se investe em manutenção de forma preventiva, caracterizando-se as atividades realizadas como manutenções corretivas. Os dados socioeconômicos levantados vêm ratificar o que já havia sido informado pelos moradores que os serviços são realizados de acordo com a disponibilidade financeira da família.

\section{CONSIDERAÇÕES FINAIS}

Os resultados obtidos nas HIS estudadas vêm demonstrar uma intrínseca relação entre a renda dos seus moradores e a respectiva manutenção das edificações.

A manutenção, tardia e com baixa qualidade técnica, teve influência preponderante das limitações financeiras das famílias. Em vários casos, os próprios serviços reparadores foram protelados indeterminadamente, agravando ainda mais a deterioração dos elementos construtivos e ampliando as suas consequências ao ambiente dos moradores.

As pessoas que executaram boa parte dos reparos foram escolhidas, provavelmente, pelo critério de economia e diminuição de custos, e raramente pela acuidade profissional. Essa realidade comprometeu o adequado diagnóstico dos problemas, a seleção de materiais e ferramentas adequadas e as técnicas de execução dos serviços.

Os dados serviram para evidenciar uma estreita afinidade existente entre a renda dos moradores das Habitações de Interesse Social selecionadas, construídas com sistema não-convencional do Projeto Mariz I, na cidade de João Pessoa e os custos com a 
manutenção das mesmas. As limitações de renda dos moradores influenciaram não só na ausência/protelação da manutenção das edificações, mas também no resultado final da sua execução, quando houve.

Vale ressaltar que o presente artigo é oriundo de uma pesquisa em andamento, a qual pretende-se dar prosseguimento aos estudos aqui explanados, objetivando, com isso, resultados ainda mais relevantes para o tema proposto.

\section{AGRADECIMENTOS}

À FINEP e ao CNPq, pelo apoio recebido.

\section{REFERÊNCIAS}

ABIKO, A. K. Introdução à gestão habitacional. São Paulo: Escola Politécnica da USP, $1995 . \quad$ Texto técnico. Disponível em: <http://publicações.pcc.usp.br/PDF/ttcap12.pdf>. Acesso em: 04 jul. 2013.

ABNT - ASSOCIAÇÃO BRASILEIRA DE NORMAS TÉCNICAS. NBR 15575: Edificações habitacionais - Desempenho. Rio de Janeiro, 2013.

NBR 5674: Manutenção de edificações - Requisitos para o sistema de gestão de manutenção. Rio de Janeiro, 2012.

ANTUNES, G. B. S. Estudo da manutenção de edifícios: percepções dos projetistas e gerente/administradores. 2004. 228 f. Dissertação (Mestrado em Engenharia). Programa de Pós-Graduação em Engenharia Civil. Universidade Federal do Espírito Santo, Vitória. 2004.

EL-HARAM, M. A.; HORNER, M. W. Factors affecting housing maintenance cost. Journal of Quality in Maintenance Engineering, v.8, n.2, p. 115-123, 2002.

FREITAS, C. R. Geração de indicadores visando a otimização da gestão da manutenção na Universidade Federal do Rio Grande do Sul. 2009. 69 f. Trabalho de Diplomação (Graduação em Engenharia Civil) - Departamento de Engenharia Civil. Universidade Federal do Rio grande do Sul, Porto Alegre.

GOMIDE, T. L. F; PUJADAS, F. Z. A; FAGUNDES NETO, J. C. P. Técnicas de Inspeção e Manutenção Predial. São Paulo: Pini, 2006.

NERI, M. C. A nova classe média: o lado brilhante dos pobres. Rio de Janeiro: FGV/IBRE, CPS, 2010.

NUNES, Angela Araújo. A atuação do Montepio na produção estatal de habitação em João Pessoa de 1932 a 1963. Dissertação (Programa de Pós-Graduação em Engenharia Urbana e Ambiental). UFPB/CT, João Pessoa, 2008. <http://www.ct.ufpb.br/pos/ppgecam/index.php/dissertacoes>. Acesso em: 28 nov. 2012.

OLANREWAJU, A. A.; IDRUS, A.; KHAMIDI, M. F. Creating maintenance cost model for university buildings. World Academy of Science, Engineering and Technology, n.60, p. 1959-1964, 2011. 
SAE (Secretaria de Assuntos Estratégicos do Governo Federal). 2014 a. Disponível em: < http://www.sae.gov.br/site/?p=17821 >. Acesso em: 22 mai. 2014.

2014 b. Disponível em: < http://www.sae.gov.br/site/?p=23161>. Acesso em: 22 mai. 2014.

TINEM, Nelci; CARVALHO, Juliano. Límites, marcos y señales. Las calles de la ciudad (João Pessoa, Brasil). In: IV ENCUENTRO INTERNACIONAL CIUDAD IMAGEN Y MEMORIA. Santiago de Cuba 20 al 23 de junio del 2005. Disponível em: <http://www.lppm.com.br/sites/default/files/livros/L\%C3\%ADmites, \%20marcos\%20y $\% 20$ se $\%$ C3\%B1ales.\%20Las\%20calles\%20de\%20la\%20ciudad.pdf $>$ Acesso em: 04 jul. 2013.

WAEYENBERGH, G.; PINTELON, L. A framework for maintenance concept development. International Journal of Production Economics, Sweden, v.77, n.3, p.299-313, 2002. 